\title{
Categorizing the Growth Strategies of Small Firms
}

\author{
Seppo Leminen and Mika Westerlund
}

\author{
"Innovation has nothing to do with how many R\&D dollars you") \\ have. When Apple came up with the Mac, IBM was spending \\ at least 100 times more on $R \& D$. It's not about money. \\ Steve Jobs \\ Designer, inventor, and co-founder of Apple Inc.
}

\begin{abstract}
This study investigates the link between a small firm's investment in R\&D and its growth strategy. A firm's growth strategy refers to the means by which the organization plans to achieve its objective to grow in volume and turnover. We categorize firm growth strategies into eight distinctive clusters: opportunity explorers, radical innovators, business developers, business expanders, profit makers, business rebuilders, stagnators, and downsizers. We argue that understanding a firm's growth orientation provides a way to assess the returns of its $R \& D$ investments, because an organization's intangible growth strategies and tangible inputs are connected.
\end{abstract}

\section{Introduction}

Understanding small-business growth strategies is today more topical than ever before. Small firms are vital contributors to economic growth and the perfect incubators of innovation (Morrison et al., 2003; tinyurl.com/cda8rzu). Achieving rapid growth is crucial to small firms (Churchill and Lewis, 1983: tinyurl.com/79uq2wx; Greiner, 1993: tinyurl.com/cnjrkhx). In order to compete, managing organizational growth has become a priority for top management teams of small firms.

Our understanding of growth strategies in the smallbusiness context is quite limited. Porter's (1996; tinyurl.com/d5rnnbg) typology for discussing corporate strategies focuses on large firms and does not properly highlight growth strategies. Therefore, some authors have suggested frameworks to identify specific growth strategies (Kirchhoff, 1994; tinyurl.com/6uwd56q), while others investigate diverse growth phases (Stremersch and Tellis, 2004; tinyurl.com/6sfgn7n). Our objective is to understand the link between a firm's $R \& D$ investment and its growth strategy.
The remainder of this article is organized into four sections. After this brief introduction, we discuss a firm's growth and its underlying strategic orientations in the context of small firms. We proceed by presenting our proposed framework, which links a small firm's R\&D investments and its growth strategy. Finally, we conclude by discussing our findings and their implications.

\section{Background on the Growth of Small Firms}

The literature on small-firm growth can be organized into three streams: i) tangible and intangible growth drivers; ii) growth stages; and iii) Schumpeterian growth models.

The first literature stream aims to understand the tangible and intangible drivers of growth. Many authors identify internal resources that firms need to systematically organize for growth (Robson and Bennett, 2000; tinyurl.com/7hzanud), whereas others focus on strategic relationships as a way to grow (Lechner and Dowling, 2003; tinyurl.com/3zxcqfl). The internationalization perspective emphasizes processes that should be adapted to shift the firm's focus from local to global operations 


\title{
Categorizing the Growth Strategies of Small Firms
}

\author{
Seppo Leminen and Mika Westerlund
}

(Coviello and McAuley, 1999; tinyurl.com/7urgaws). According to the cognitive approach, organizational intention and ability (Morrison et. al., 2003; tinyurl.com/cda8rzu), leadership and talent (Gandossy, 2005; tinyurl.com/ c7rfbnn), and growth aspiration (Glancey, 1998; tinyurl.com/8x7ax9k) are necessary conditions for growth. In addition, intangible resources are just as important determinants of firm success than tangible resources (Galbreath, 2004; tinyurl.com/8y7klr2).

The second literature stream on firm growth examines the various stages of growth. Conceptualizing the growth of organizations by describing their transitions through a series of stages, from birth to maturity, has considerable intuitive appeal (Phelps et al., 2007; tinyurl.com/6mjq3vb). For example, the development of relationships with partners provides the needed resources for the rapid scaling-up of production, but utilizing a growth opportunity may later require a new set of allies (Hite and Hesterly, 2001; tinyurl.com/6w5x4zl). The stage approach also asserts that there are several growth challenges due to design flaws in each stage. However, the life-cycle hypothesis that underlies this perspective (i.e., the assumption that growth is linear, sequential, deterministic, and invariant) has recently been argued not to pertain (Phelps et al., 2007; tinyurl.com/6mjq3vb). Although the critical argument may not completely hold, growth does seem to be a more complex phenomenon.

The third literature stream comprises Schumpeterian growth models. It is a particular type of economic growth that is generated by the endogenous introduction of product or process innovations (Dinopoulos, 2009; tinyurl.com/77earot). Schumpeterian growth apprehends the benefits that result from the destruction of old products and processes by new ones. This perspective explains growth by innovation and entrepreneurial spirit and suggests $R \& D$ investments as antecedents to organizational growth and performance (Wolff and Pett, 2006; tinyurl.com/72d62l3). The relationship between financial $R \& D$ investments and returns is based on the selected strategy and type of operations, because increasing or decreasing $R \& D$ investments are strategic inputs that affect the magnitude and timing of future revenue (Lantz and Sahut, 2005; tinyurl.com/6wvywe2). Innovation-based growth is crucial for small firms.

\section{Underlying Strategic Orientations}

Strategic orientation refers to the formulation of strategies with long-term objectives. It consists of both strategic intent and actual behaviour (Siguaw et al.,
2006; tinyurl.com/6nzfw5j). Entrepreneurs use it to guide the efforts in the organization, because it "reflects strategic directions implemented by a firm to create the proper behaviours for the continuous superior performance of the business" (Gatignon and Xuereb, 1997; tinyurl.com/6uomxlf). In this study, we focus on two types of complementary strategic orientations: innovation orientation and growth orientation.

Innovation orientation consists of market orientation and technology orientation. Market orientation describes a firm's posture towards creating an understanding of its customers and serving customer needs (Narver and Slater, 1990; tinyurl.com/ca6bvy). Its positive impact on organizational performance is widely acknowledged, but it reflects a reactive posture given that it concentrates on the expressed needs of current customers. Technology orientation describes a firm's posture towards engaging in technological research and development, in analyzing technology potentials, and in forecasting technology trends (Gatignon and Xuereb, 1997; tinyurl.com/6uomxlf). It manifests in the acquisition of substantial technological expertise and in the investment in technological leadership (Talke et al., 2011; tinyurl.com/6nrcj4r). Markets and technology are alternative directions of innovation orientation; however, we use the term innovation instead of technology, because many firms develop services. Consequently, small businesses focus on either exploiting markets or exploring for innovation.

Growth orientation refers to the entrepreneur's desire to achieve growth. Most firms, of course, desire growth to prosper and survive. High-growth orientation means that rapid growth is the top priority, while low-growth orientation means safe, slow, and steady growth are priorities for management (Brown et al., 2001; tinyurl.com/6sv2mja). However, not all firms are targeting to grow and maximise their returns. Some entrepreneurs avoid risk and responsibility by limiting undesired growth. According to the results of a Norwegian survey, nearly 40 percent of the entrepreneurs did not want their firms to grow at all and nearly two-thirds did not want their firms to grow in terms of employment (Kolvereid, 1992; tinyurl.com/7a7q7tw). Firms are either growth- or control-oriented.

\section{Growth-Strategy Framework}

In this study, we establish a framework to describe four diverse growth strategies of small firms using innovation orientation and growth orientation as dimensions. These growth strategies are: i) explore, ii) expand, iii) ex- 


\section{Categorizing the Growth Strategies of Small Firms}

Seppo Leminen and Mika Westerlund

ploit, and iv) restrain. They are supported by literature on small business growth (Davidsson et al., 2002: tinyurl.com/7c7plqk; Chan et al., 2006: tinyurl.com/7wjwc3d; Morrison et al., 2003: tinyurl.com/cda8rzu) and each strategy is a result of the underlying organizational orientations. In addition, we include two dimensions describing "investments" as tangible inputs and "returns" as outputs to complement the intangible growth strategies as suggested by Kirchhoff (1994; tinyurl.com/ 6uwd56q). They describe a firm's R\&D expenses and the attained performance in terms of revenues.

We maintain that a firm's growth strategy not only defines its R\&D investments, but also affects the expected returns. We further see that innovation matures typically following a counter-clockwise cycle; starting from an "Explore" strategy. However, a firm can opt for any strategy or even skip phases during the evolution. Consequently, the framework provides us with eight categories of small firm growth (Figure 1).
1. The "explore" strategy accentuates the firm's innovation development efforts

Firms that explore their path to growth need to be innovation oriented. In the long run, it is necessary for the firm to explore new possibilities and to develop new competencies. Exploration refers to a firm's capturing of competences through activities characterized by search, variation, risk taking, experimentation, play, flexibility, discovery, and innovation (Gupta et al., 2006; tinyurl.com/cuvnelj). Competitiveness can be guaranteed only through innovation activity, which allows survival in the market competition. However, innovation activity calls for heavy investments in research and development. Therefore, exploring firms stand on unstable grounds since they have high level of investments, but gain little or no profits from the new product introduction (Homburg et al., 2002; tinyurl.com/d3u79m2).

The relationship between the $R \& D$ investments and returns reveals whether the firm is an opportunity ex-

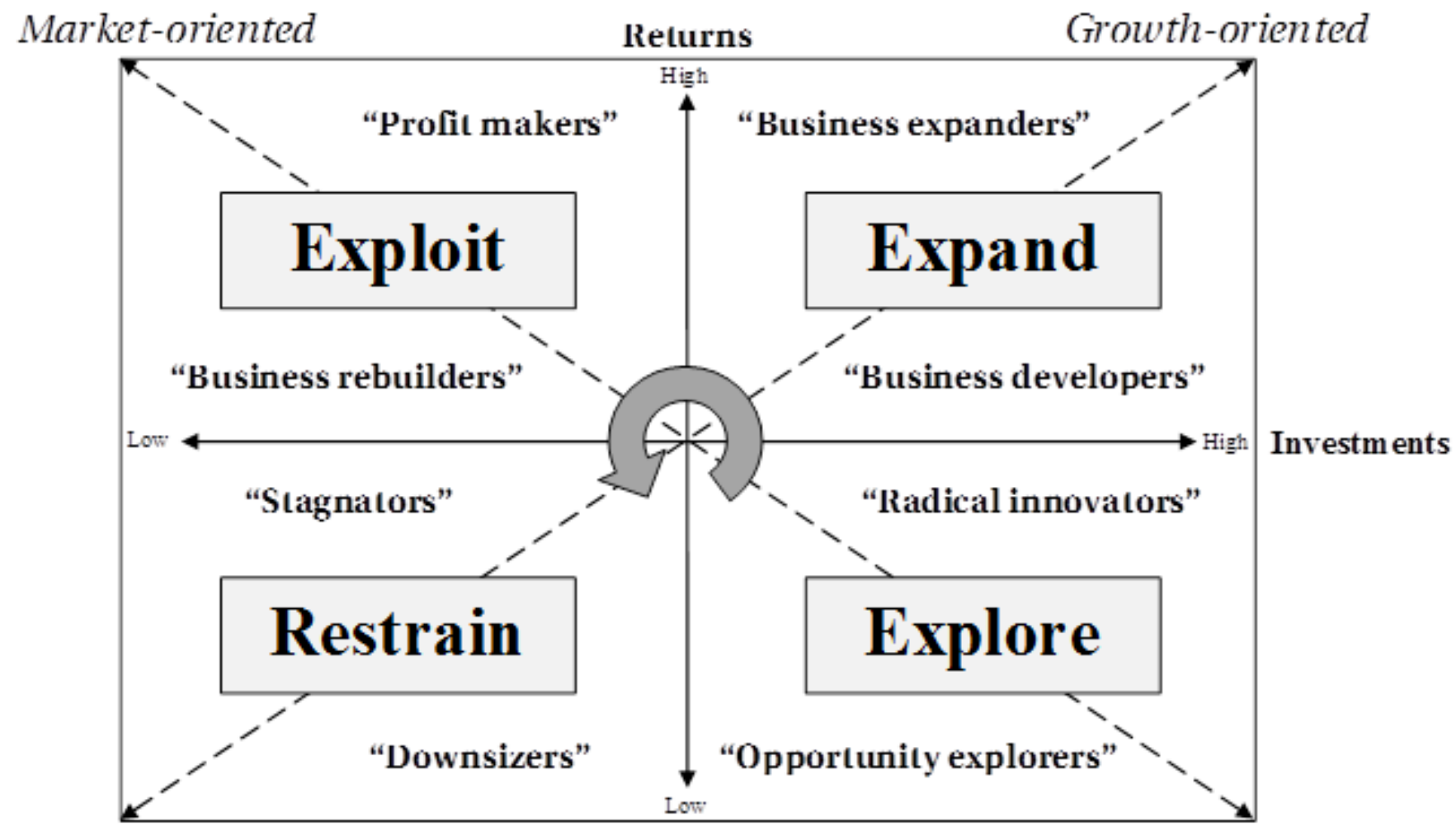

Control-oriented

Innovation-oriented

Figure 1. Framework of small-firm growth strategies and the counter-clockwise cycle of innovation maturity 


\section{Categorizing the Growth Strategies of Small Firms}

\section{Seppo Leminen and Mika Westerlund}

plorer scanning potential technologies and market opportunities that could generate future innovations and revenues. It can, for example, search for new technological capabilities (Koza and Lewin, 1998; tinyurl.com/7wgc4rk). At this point, returns are at low levels because there is no concrete prospect to grab on or the development work is at an early stage. Alternatively, the firm may be radical innovator that challenges its competitors by proactively investing in the development of breakthrough technology. Innovation development has shifted from mere opportunity seeking into a product or service development plan and introduction.

\section{The "expand" strategy reveals the firm's eagerness for growth}

The expand strategy suggests that a firm is growth-oriented with a high level of investments and a high level of returns. It refers to a firm's expansion to new markets and customer domains. However, small businesses face numerous constraints to growth such as limited capital, time, experience, and information resources. Therefore, this strategy is challenging yet profitable. Growth aspiration is the most important discriminating characteristic between growth-oriented and nongrowth oriented entrepreneurs (Delmar et al., 2003; tinyurl.com/6spud97). It promotes a path-dependent and self-reinforcing progression toward permanently faster growth (Eisenhardt and Schoonhoven, 1990; tinyurl.com/89c2lld) and is positively associated with sales growth (Delmar et al., 2003; tinyurl.com/6spud97).

A firm following the expand strategy may be a business developer targeting to develop its business processes into a better functioning entity. Alternatively, the firm may develop its commercialization methods and begin voluminous selling of the innovation. Investments in process development typically result in only moderate increases in returns, unless the staff's growth-oriented mentality enables the firm to fully utilize the inputs. Conversely, if the return on investments ratio is high, the firm may aim at rapid expansion of its business. For example, internationalization is fundamental to the rapid growth of firms in the contemporary business environment (Hadley and Wilson, 2003; tinyurl.com/ 83m4fhh). Such a small firm becomes a business expander with a high investment rate and a high level of returns.

\section{The "exploit" strategy highlights the organization's profit-making objective}

Firms utilizing the exploit strategy should be market oriented. Kohli and Jaworski (1990; tinyurl.com/82wqnrx) define market orientation as the generation of market intelligence pertaining to current customer needs and the firm's responsiveness to it. Market-oriented firms exploit the existing resources in an efficient way. Exploitation includes refinement, choice, production, efficiency, selection, implementation, and execution as approaches in resource capturing (March, 1991; tinyurl.com/8xqlyp5). It consists of only a petty refinement of existing technology, because the exploitative firm sustains a price competition with a high-level profit objective. Market orientation and business performance have a strong positive link, particularly in small firms (Golann, 2006; tinyurl.com/7cv2z6a).

An exploiting strategy means that small firms have a low rate of $R \& D$ investment and a high level of returns. It enables them to exploit the market and generate immense cash flows. Companies typically move from exploration to exploitation along with the maturation of innovation. Whereas explorers invest copiously to create novel offerings for future markets, exploiters cash in the current ones. Investments in the production technology and adaptation to customer's needs may yield excessive profits and the small firm becomes a profit maker. Conversely, business rebuilders cut off $\mathrm{R} \& \mathrm{D}$ investments and acquire profitability through marketing spending, but this approach is effective only in the short run. Many Internet businesses spent heavily on marketing, but after the bubble burst, most of this spending stopped. Firms need to rebuild their businesses to avoid disappearance due to fierce competition and decreasing price margins.

\section{The "restrain" strategy means controlling unwelcome organizational growth}

The restrain strategy pertains to the manager of a small business who is reluctant to grow the business. The growth of firm and the business is restrained by controlling the activities of the staff and the operations of the firm (Eisenhardt, 1985; tinyurl.com/87ye9xf). The behaviour with this strategy manifests in low levels of investment and low level of returns. Although it can be just a responsive action to a firm's financial predicament, many entrepreneurs refuse to enlarge their firms beyond a specific number of employees. In fact, they try to reduce the undesired growth. There are several motives for restraining strategy, such as self-employment instead of profit maximisation. Firms following the restrain strategy have generally low rates of growth (Glancey, 1998; tinyurl.com/8x7ax9k).

Labour costs are common incentives for decreasing R\&D investments (Cordis, 2006; tinyurl.com/c47at2m). However, they are not a major problem when either re- 


\section{Categorizing the Growth Strategies of Small Firms}

\section{Seppo Leminen and Mika Westerlund}

turn on investments or operating margins are high. Considering that the restrain strategy suggests low returns and low margins, stagnators try to keep their businesses above the surface as long as they can. They either avoid the growth or have exceeded the time limit of exploiting market as a business rebuilder. Their trivial investments do not allow the growth of profits; rather they keep them at the current level or with a downward trend. Similarly, the restrain strategy is preferred by downsizers, who intentionally avoid risks of growth or who consider ending their business, for example due to the entrepreneur's retirement. Even this reaction to unsolicited growth can be profitable for a while.

Our framework also has limitations. Similar to other studies on firm growth, we accept that an endogenous growth strategy is not exclusive, because: i) growth may be affected by changes in the industry, ii) the effective size of businesses may vary by the sector, and iii) some industries are more capital-intensive than others. Furthermore, there are low-cost ways to invest in $R \& D$, such as participating in the open innovation development. These aspects should be considered when applying the framework.

\section{Conclusion}

Our objective was to understand the role of tangible and intangible resources in small business growth. To grow, a small firm requires investment and the desire to grow. In small firms, investment decisions and outcomes are connected via the firm's growth strategy. Because small businesses have diverse strategic orientations regarding innovation and growth, this connection allows us to identify different clusters of firm growth. These clusters are not stagnant but evolutionary. Typically, business innovation matures in a counter-clockwise cycle, starting from exploration and shifting towards exploitation as the offering or business matures. However, the firm can skip phases or opt for any specific cluster at any time regardless of the cycle. Nonetheless, companies need to start the cycle again to avoid the survival trap.

\section{About the Authors}

Seppo Leminen, D. Sc. (Econ.), Lic. Tech., holds positions as Principal Lecturer at the Laurea University of Applied Sciences and Adjunct Professor in the School of Economics at Aalto University. Seppo holds a doctoral degree in Marketing from the Hanken School of Economics and a licentiate degree in Information Technology at the Helsinki University of Technology. His research and consultation interests include value co-creation and capture with users as well as relationships, services, and business models in marketing. He runs various living lab and business model projects in ICT and media industries.

Mika Westerlund, D. Sc. (Econ.) is an Assistant Professor at Carleton University's Sprott School of Business. He previously held positions as Postdoctoral Scholar in the Haas School of Business at the University of California Berkeley and Postdoctoral Researcher in the School of Economics at Aalto University. Mika earned his doctoral degree in Marketing from the Helsinki School of Economics. His doctoral research focused on software firms' business models and his current research interests include open innovation, business strategy, and management models in high-tech and service-intensive industries. Results from his research are reported in numerous scholarly journals.

Citation: Leminen, S. and M. Westerlund. 2012.

Categorizing the Growth Strategies of Small Firms.

Technology Innovation Management Review. May 2012: 5-9. 